\title{
Review Article \\ Copper Oxide Nanomaterials Prepared by Solution Methods, Some Properties, and Potential Applications: A Brief Review
}

\author{
Thi Ha Tran ${ }^{1}$ and Viet Tuyen Nguyen ${ }^{2}$ \\ ${ }^{1}$ Hanoi University of Mining and Geology, Co Nhue, Tu Liem, Hanoi 130503, Vietnam \\ ${ }^{2}$ College of Science, Vietnam National University, 334 Nguyen Trai, Thanh Xuan, Hanoi 120034, Vietnam \\ Correspondence should be addressed to Viet Tuyen Nguyen; nguyenviettuyen@hus.edu.vn
}

Received 22 April 2014; Revised 27 October 2014; Accepted 23 November 2014; Published 17 December 2014

Academic Editor: Saveria Santangelo

Copyright (c) 2014 T. H. Tran and V. T. Nguyen. This is an open access article distributed under the Creative Commons Attribution License, which permits unrestricted use, distribution, and reproduction in any medium, provided the original work is properly cited.

Cupric oxide $(\mathrm{CuO})$, having a narrow bandgap of $1.2 \mathrm{eV}$ and a variety of chemophysical properties, is recently attractive in many fields such as energy conversion, optoelectronic devices, and catalyst. Compared with bulk material, the advanced properties of $\mathrm{CuO}$ nanostructures have been demonstrated; however, the fact that these materials cannot yet be produced in large scale is an obstacle to realize the potential applications of this material. In this respect, chemical methods seem to be efficient synthesis processes which yield not only large quantities but also high quality and advanced material properties. In this paper, the effect of some general factors on the morphology and properties of $\mathrm{CuO}$ nanomaterials prepared by solution methods will be overviewed. In terms of advanced nanostructure synthesis, microwave method in which copper hydroxide nanostructures are produced in the precursor solution and sequentially transformed by microwave into $\mathrm{CuO}$ may be considered as a promising method to explore in the near future. This method produces not only large quantities of nanoproducts in a short reaction time of several minutes, but also high quality materials with advanced properties. A brief review on some unique properties and applications of $\mathrm{CuO}$ nanostructures will be also presented.

\section{Introduction}

In recent years, nanostructures of transition metal oxides have gained a great attention from material scientists and engineers due to their different properties compared with the corresponding bulk counterparts, which in turn provides promising applications in various fields of technology. Preparation of high quality nanostructures of defined, controllable size and morphology is a critical requirement in order to develop nanodevices or other different applications for catalyst, sensing, pharmacy [1-7], and so on.

$\mathrm{CuO}$, categorized into transition metal oxide group, is a $\mathrm{p}$ type, narrow bandgap semiconductor. It has monoclinic structure and many interesting characteristics: super thermal conductivity, photovoltaic properties, high stability, and antimicrobial activity. Due to such exclusive properties, $\mathrm{CuO}$ can be used in many technological fields, for example, active catalyst [1], gas sensor $[4,6]$, high efficiency thermal conducting material [7], magnetic recording media [8], with very good selectivity, or solar cell applications [9].

In addition to some shared properties of metal oxide nanostructures, such as $\mathrm{TiO}_{2}, \mathrm{ZnO}, \mathrm{WO}_{3}$, and $\mathrm{SnO}_{2}, \mathrm{CuO}$ nanostructures have other unique magnetic and superhydrophobic [10] properties. Furthermore, these nanostructures show very promising applications in heterogeneous catalysis in the complete conversion of hydrocarbons into carbon dioxide, enhancement of thermal conductivity of nanofluid, nanoenergetic materials, and super-hydrophobic surfaces or anode materials for lithium ion batteries (LIBs). However, this material has not got attention of scientists at right level until recent years. Compared with other oxides of transition metal such as $\mathrm{Fe}_{2} \mathrm{O}_{3}, \mathrm{TiO}_{2}$, and $\mathrm{ZnO}$ only few reports have described the synthesis strategies adopted for $\mathrm{CuO}$ nanostructures along with the introduction of their related applications. 
In this paper we would like to systematically discuss the effect of some factors in solution based process on the nanoproducts rather than focus on each individual synthesis process. For each factor, critical comments will be provided based on our knowledge and related research experience. Some properties and potential applications of $\mathrm{CuO}$ nanostructures reported in the literature to date will also be presented. This review aims to provide a critical discussion of the synthesis of $\mathrm{CuO}$ nanostructures. The potentials of $\mathrm{CuO}$ nanostructures as functional components for fabrication of micro/nanodevices are also evaluated and highlighted. In particular, we focus on the fundamental properties and various nanostructured forms of $\mathrm{CuO}$ that have been reported in the literature to date and summarize the various synthetic strategies. Precisely controlling the synthetic strategies is very critical because it helps to obtain $\mathrm{CuO}$ nanostructures with manageable dimensions and morphology which is crucial for obtaining corresponding unique properties. This in turn enables a variety of promising applications that would not be possible for bulk material. The aim of this review is to provide critical discussion about important factors that can affect morphologies and size of $\mathrm{CuO}$ nanoproducts prepared by solution methods. The review hopefully can contribute some useful information that helps to better understand the relation between synthetic process, final morphology, and the properties of corresponding $\mathrm{CuO}$ nanostructures. A better understanding of the fundamental properties of $\mathrm{CuO}$ nanostructures is essential for their application as building blocks for functional devices.

\section{Synthesis of $\mathrm{CuO}$ Nanostructures}

The development of synthetic methods has been widely accepted to contribute an important part to fundamental study for understanding properties and realizing applications of nanoscale materials. It allows material scientists to control different parameters of the products such as shape, particle size, size distribution, and composition. Numerous methods such as thermal evaporation, sonochemical, sol-gel, hydrothermal, and electrochemical methods $[2,11-15]$ and microwave irradiation approach [16-18] have been developed to synthesize $\mathrm{CuO}$ nanostructures with diverse morphologies, sizes, and dimensions using various chemical, physical, or chemistry physics combined strategies. This paper focuses only on direct solution methods to successfully prepare copper (II)-oxide $(\mathrm{Cu}=\mathrm{O})$ nanostructures with different sizes, shapes, some of their properties and different applications in daily life and technology. The main reason why we would like to limit our considerations only to the wet chemical methods is that these approaches offer many advantages compared with physics synthesis processes such as the possibility to use low cost and high-throughput equipment, low wastage of raw materials, high uniformity of size and shape of the nanoproduct, and, finally, potential deployment of large scale production with low capital investment.

In this review, we would like not to present the synthetic strategies in detail but rather to discuss the effect of major factors of the synthetic process such as solvents, starting materials, and additive materials on $\mathrm{CuO}$ nanoproducts.
A typical direct solution method to prepare $\mathrm{CuO}$ nanostructures usually involves the following steps: preparing the precursor solution, modification of nanoproducts with additives or surfactants, heat treatment, and washing and drying process.

$\mathrm{CuO}$ nanoproducts are prepared according to the following equations:

$$
\begin{aligned}
& \text { Copper salt }+ \text { Alkaline hydroxide } \\
& \longrightarrow \mathrm{Cu}(\mathrm{OH})_{2}+\text { Salt of alkaline metal } \\
& \mathrm{Cu}(\mathrm{OH})_{2} \longrightarrow \mathrm{CuO}+\mathrm{H}_{2} \mathrm{O}
\end{aligned}
$$

The entire process was summarized by the diagram in Figure 1.

In the next part, we will discuss in detail possible effects of each factor on the morphology and properties of final products.

\subsection{Effect of Starting Materials}

2.1.1. Solvent. Solvent is one of the most important components of wet chemical methods as solvent has a crucial effect on the product. Due to the critical role of solvent, it is sometimes used to name a particular wet chemical approach, for example, alcohol-thermal synthesis or DMSO (dimethyl sulfoxide) route. Two primary criteria for the solvents used to synthesize $\mathrm{CuO}$ nanostructures are as follows: (i) they dissolve copper and alkali hydroxide compounds and (ii) they can be washed away easily or decomposed during the washing and drying process without leaving any detrimental impurities or residues in the final nanoproduct. There are many secondary factors that great attention should be paid for the synthesis process such as viscosity, surface tension, volatility, reactivity, toxicity, and cost.

In order to dissolve well copper salts and alkali hydroxide, which are ionic compounds, polar solvents are normally used for synthesizing $\mathrm{CuO}$ nanostructures. Water is certainly the cheapest, safest, and most environmentally friendly solvent. In fact, in most of the reports, $\mathrm{CuO}$ nanostructures were prepared by utilizing water as solvent; however, there are only few reports of using water solely without any additives or surfactants (see Table 1). Preparation of nanostructures in water without any additives normally leads to large (several hundreds of nanometers) and nonuniform size and shape particles or complex structures like 3D flower-like structures. These results imply that water itself has some disadvantages that make scientists prefer to use other organic solvents such as alcohols of different carbon chain length or number of functional groups $(\mathrm{OH})$. The main disadvantage of using water as solvent is that water tends to promote the coarsening process during the growth of nanostructures prepared from liquid phase. Coarsening involves the growth of larger crystals at the expense of smaller crystals and is governed by capillary effects. Since the chemical potential of a particles increases with decreasing particle size, the equilibrium solute concentration for small particles is much higher than that for large particles or, in other words, larger particles are more energetically favored than smaller particles. The resulting 


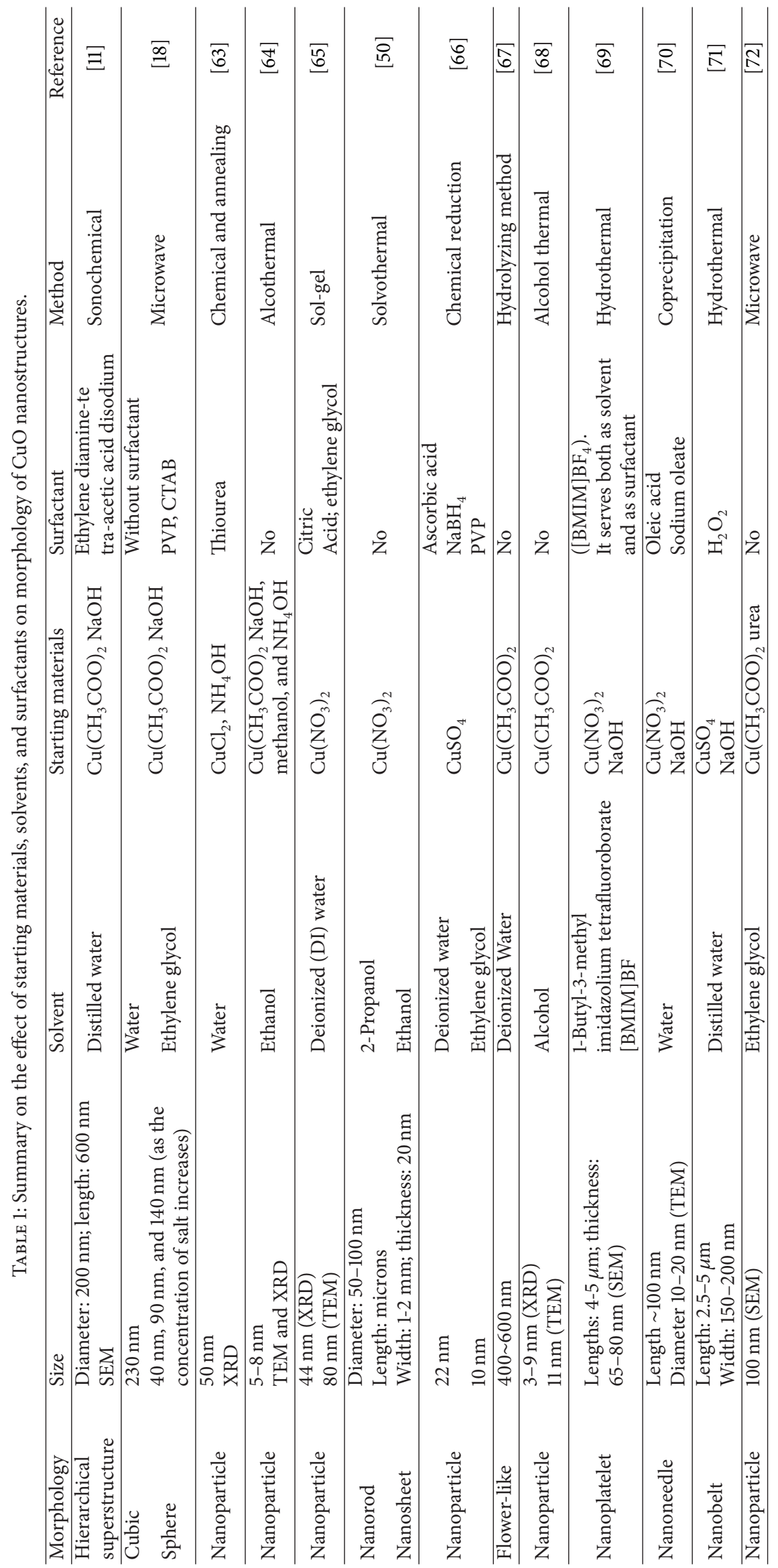




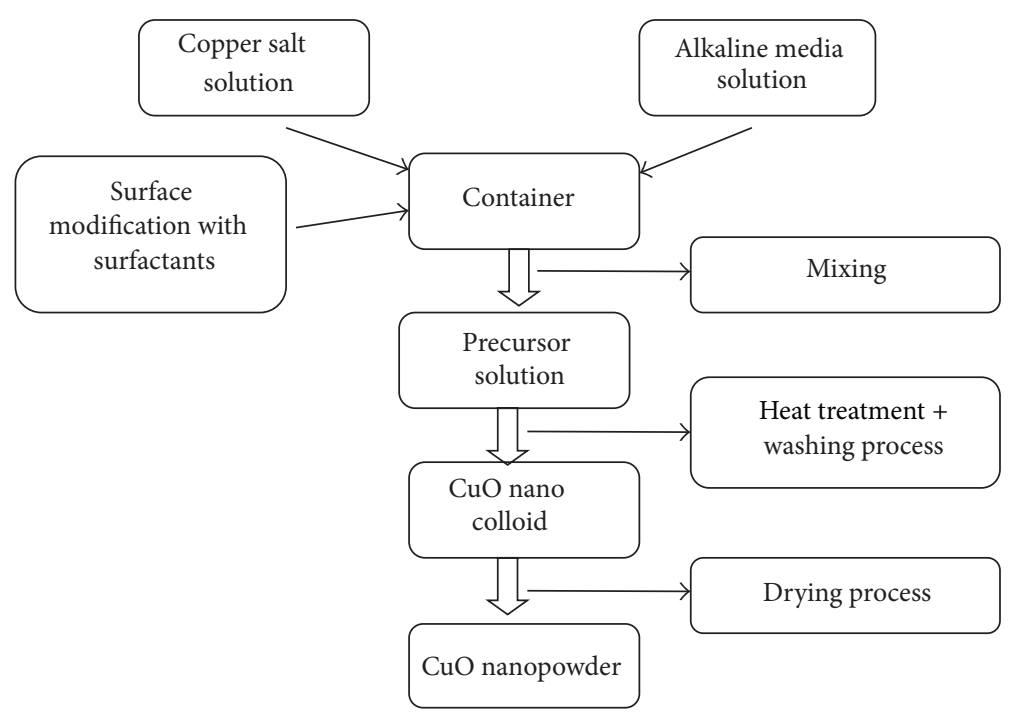

FIGURE 1: Schematic diagram of a typical direct solution synthesis of $\mathrm{CuO}$ nanostructures.

concentration gradients lead to transport of solute from the small particles to the larger particles. The rate law for this process, derived by Lifshitz, Slyozov, and Wagner (LSW) [19], is given by

$$
\bar{r}^{3}-\bar{r}_{o}^{3}=k t,
$$

where $\bar{r}$ is the average particle radius, $\bar{r}_{o}$ is the average initial radius, $k$ is the rate constant, and $t$ is time. The rate constant $k$ is given by

$$
k=\frac{8 \gamma V_{m}^{2} c_{r=\infty}}{54 \pi \eta a N_{A}},
$$

where $\gamma$ is the surface energy, $V_{m}$ is the molar volume, $c_{r=\infty}$ is the equilibrium concentration at a flat surface (i.e., the bulk solubility), $\eta$ is the viscosity of the solvent (at room temperature, $\eta_{\text {water }}=8.94 \times 10^{-4} \mathrm{~Pa} \cdot \mathrm{s}, \eta_{\text {absolut ethanol }}=10.74 \times$ $10^{-4} \mathrm{~Pa} \cdot \mathrm{s}$ and $\left.\eta_{\text {iso propanol }}=19.45 \times 10^{-4} \mathrm{~Pa} \cdot \mathrm{s}[19]\right)$, and $a$ is the solvated ion radius.

From (4) it is apparent that the rate constant $k$ is inversely proportional to $\eta$ if $c_{r=\infty}$ and $\gamma$ are independent of the solvent. The viscosity of water is several times higher than the viscosity of alcohols such as ethanol or isopropanol, and hence the coarsening process of nanostructures in water takes place much faster and results in big agglomerated clusters.

In addition, the polarity of water is also more favorable for the formation of large agglomerated clusters. The idea that polarity of solvent can alter the morphology of nanoparticles was reported theoretically and experimentally by the group of Leekumjorn [20]. In their report, the authors showed that solvent polarity has a better correlation with the simulation and experimental results than other parameters such as dielectric constant or dipole moment. Computational results showed that the nonpolar solvents of hexane, toluene, and benzene (polarity index $E_{N}^{T}<0.120$ ) kept oleate-capped nanoparticles in suspension and solvated the oleate chains so that the oleate layer swelled to full extension. In contrast, as the most polar solvent tested $\left(E_{N}^{T}=1.000\right)$, water caused nanoparticles to aggregate and precipitate. For solvents of intermediate polarity like ethanol, acetone, and chloroform, quantum dots were colloidally stable in solvents below a critical polarity index value $\left(E_{N}^{T}=0.307\right)$.

Some other organic solvents rather than water have been also tested for the synthesis of $\mathrm{CuO}$ nanostructures. Different alcohols will then be the next choice to synthesize copper oxide nanoparticles due to their excellent characteristics as solvents. Alcohols have a very polar hydroxyl $(\mathrm{OH})$ group, with the high electronegativity of oxygen allowing hydrogen bonding to take place with other molecules. Also, alcohols have nonpolar carbon chains; therefore, they can dissolve both polar and nonpolar substances, while water can dissolve only polar ones. Alcohols are low toxic, and ethanol is the least toxic of the alcohols, which makes it more suitable for use in industry and consumer products. The most common used alcohols are ethanol (boiling point $78.4^{\circ} \mathrm{C}$ ), glycerol $\left(290.0^{\circ} \mathrm{C}\right)$, propanol $\left(97^{\circ} \mathrm{C}\right)$, propylene glycol $\left(188.2^{\circ} \mathrm{C}\right)$, and ethylene glycol $\left(197.3^{\circ} \mathrm{C}\right)$. Another advantage of alcohols is that they could be removed easily during the washing process without leaving unwanted impurities on the products. Because in liquids phase process, $\mathrm{CuO}$ nanoparticles were formed through the decomposition of $\mathrm{Cu}(\mathrm{OH})_{2}$, organic solvents of boiling points higher than the decomposed temperature of $\mathrm{Cu}(\mathrm{OH})_{2}$ should be chosen. However, copper hydroxide is decomposed into copper oxide at a quite low temperature, which is only $80^{\circ} \mathrm{C}$; then most of alcohols fulfill those criteria and can be utilized to prepare $\mathrm{CuO}$ nanostructures. Even ethanol, of which boiling point $\left(78.4^{\circ} \mathrm{C}\right)$ is slightly lower than the decomposed temperature of $\mathrm{Cu}(\mathrm{OH})_{2}$, could be used. However, following the above discussion, as the carbon chain gets longer, alcohols become less polar and have higher viscosity; it is more favored for synthesis of small, uniform, and nonaggregated nanoparticles.

Some other organic solvents such as, dimethylformamide (DMF) and dimethyl sulfoxide (DMSO) were also used but 
only in a few publications and the influence of solvent on the size and shape of the product was not well discussed.

2.1.2. Salt and Alkali Metal Solution. In principle, any kind of soluble copper salts could be used as precursor to prepare $\mathrm{CuO}$ nanostructures without much difference or at least there seems to be no report on the influence of copper salt precursor. Various copper salts such as chloride, nitrate, sulfate, acetate were used to prepared $\mathrm{CuO}$ nanomaterials, however the effect of different copper salts were not discussed in details. However, particle size and uniformity of copper nanoparticles prepared from copper acetate seem better than those from inorganic copper salt. A reasonable explanation is that carboxylate groups are still adsorbed on the surface of the copper oxide nanoparticles and play the role of a surfactant and suppress nanoparticles from growth and aggregating process.

The other main necessary precursor for synthesizing $\mathrm{CuO}$ nanoparticles is the base agent which provides hydroxyl ion to react with copper salt and gives the $\mathrm{Cu}(\mathrm{OH})_{2}$ precipitation. The most common used precursors are sodium hydroxide and potassium hydroxide. $\mathrm{NaOH}$ seems to be more preferred just because it is much less expensive than $\mathrm{KOH}$, while both compounds give almost the same effect due to their similar properties. $\mathrm{NH}_{4} \mathrm{OH}$ could also be utilized; however, the high volatility of $\mathrm{NH}_{4} \mathrm{OH}$ brings some limitation during the synthesis process and, hence, $\mathrm{NH}_{4} \mathrm{OH}$ appears only in few reports of preparing $\mathrm{CuO}$ nanoparticles. Sun et al. reported that using ammonia may enhance the agglomeration of the products due to the high polar nature of ammonia [21].

Mole ratio between copper ion and $\mathrm{OH}^{-}$group should be 1:2 according to (1), (2); however, many salts of $\mathrm{Cu}$ readily hydrolyze in water and thus induce high solution acidity $(\mathrm{pH}$ $<2$ ), while $\mathrm{pH}$ can play an important role in the dynamic process during the reaction. Hence, the $\mathrm{Cu}^{2+} / \mathrm{OH}^{-}$ratio in the precursor solution could be adjusted from report to report in order to obtain the nanoproduct of desired morphology and size.

A slower reaction rate, which leads to small size and narrow size distribution of the products, can be achieved by using low concentration of reactants. However, if the concentration of $\mathrm{Cu}$ salts was too low, the amount of the $\mathrm{CuO}$ product would become negligible. Concentrations that were too high, on the other hand, make the product agglomerate so the concentration of precursor solution should be chosen carefully to balance between the quantity and quality which refers to small size and good separation of the nanoproduct. Limitation of using low concentration solution could be an obstacle to the mass production of nanoproduct due to the wastage of solvent, but recycle of the used solvent could be a solution for such problem.

2.1.3. Surfactant. After the nucleation and growth process are completed, the average size of $\mathrm{CuO}$ nanoparticles could continue to increase due to agglomeration. This process reduces the quality of $\mathrm{CuO}$ nanoparticles in particular and nanoproducts in general, so restraining the particles from self-aggregating is a very important task.
As the nanoparticles were agglomerated, it is challenging to separate them. In nanostructure fabrication and processing, it is difficult to prepare small nanoparticles due to the challenge in huge surface energy; then preventing the as produced nanoproducts from aggregating together is also a real problem that is needed to be solved. There are two main stabilization mechanisms: electrostatic and steric stabilization. Electrostatic stabilization keeps the system at kinetic equilibrium while steric stabilization keeps the system at thermodynamically stable case.

Electrostatic stabilization is based on the repulsion between equally charged particles. By considering the combination of van der Waals attractions and electrostatic repulsion Derjaguin, Landau, Verwey and Overbeek successfully proposed a theory to describe the electrostatic stabilization of colloidal nanoparticles. Even though some of the assumptions in the DLVO theory [22], which is named after the scientist, such as infinitely flat surface or constant charge density of the particles, were far from reality, it explained well interaction between two approaching particles and hence is widely accepted by the science comunity.

However, there is no report of using electrostatic solely to stabilize the $\mathrm{CuO}$ nanoparticles prepared in liquid phase. Instead, most groups used various surfactants to provide the steric barrier or to combine both mechanisms to achieve the best result in preventing the $\mathrm{CuO}$ nanoproduct from aggregation. Normally, surfactants have a hydrophilic head and a hydrophobic tail. The polar heads of surfactants are absorbed on to the surface of nanoparticles, while the hydrophobic tail provides the steric repulsion to stop agglomeration. To provide sufficient repulsion between nanoparticles, the length of the stabilizer needs to be significantly longer than the characteristic size of the nanoparticles and also the polar head must have a tight bonding with nanoparticles. That is the reason why stabilizers are often high molecular weight polymers. Depending on the nature of each different polymer, another beneficial effect that surfactant may bring is to increase viscosity of the liquid media and thus minimize the rate of coarsening, as presented in the previous part.

It is extremely useful if both stabilization mechanisms above were achieved at the same time. Many groups had taken advantages of such combination by using certain polymers, of high ion density. The ionic nature of the polymer results in the electrostatic repulsion between nanoparticles while the long polymer chain simultaneously keeps the nanoparticles away from each other by steric effect. Among the polymers of this kind, polyvinylpyrrolidone (PVP) is one of the most commonly used as it can be dissolved in both polar and nonpolar solvents; the polar amide group in polymeric chain of PVP is readily attached to the surface of nanoparticles to protect them from aggregation by the two stabilization mechanisms. When dissolved into a solvent, these polymers will form a network, which can also play as templates to guide the growth of nanoproducts. It is then the network formed by polymer that could alter the morphology of the nanostructures.

Although polymer stabilizers are introduced primarily to form a layer on the surface of nanoparticles, occupy the growth sites, and reduce the growth rate of nanoparticles so 
as to prevent agglomeration of nanoparticles, the presence of such polymer stabilizers during the formation of nanoparticles can have various influences on the growth process of nanoparticles. Interaction between the surface of a solid particle and polymer stabilizer or stabilizer with each other may vary significantly depending on the surface chemistry of solid, the polymer, solvent, and temperature. The complicated dynamic process of the interaction between polymer and nanoparticles leads to a strong dependence of morphology and size of nanoparticles on type of surfactants or even the amount of surfactant that was used. Further increasing the amount of polymer in the reaction mixture was found usually to increase the sphericity of the particles. It can be easily understood by considering the fact that increased amount of polymer produces steric resistance for the diffusion and consequently results in a diffusion controlled growth, which favors the formation of spherical particles.

2.2. Solution Methods to Prepare $\mathrm{CuO}$ Nanostructures. $\mathrm{CuO}$ nanoproducts could be prepared by various methods such as sol-gel, spray pyrolysis, precipitation, solvothermal or sonochemical methods. Each method more or less has some limitations; for example, solvothermal could be used to prepare material in extreme conditions such as high temperature, high pressure; the bad side is that it takes quite long time, sol-gel process is quite complicated, and there are so many parameters need to be controlled. Among the methods that could be applied to synthesize nanomaterials, microwave irradiation method which is a chemistry physics combined method currently shows its many advantages and cut down the number of limitations, which are usually brought by other methods.

Microwave energy is a very efficient means of heating. Chemical reactions that took long time to complete can now be accomplished in minutes with the aid of microwave. Microwave assisted synthesis not only helps in implementing green chemistry but also led to the revolution in organic synthesis. Microwave irradiation is well known to promote the synthesis of a variety of compounds, where chemical reactions are accelerated because of selective absorption of microwave by polar molecules. It was found that the main advantages of microwave irradiation method compared with conventional method are fast, mild, energy-efficient, and friendly with the environment. The effectiveness of microwave irradiation in the preparation of nanoparticles can be explained by the preeminent advantages of microwave as a means of heating. The mechanism of traditional heating process is conductive heat or heating by convection currents and hence this is a slow and energy inefficient process due to the energy lost at the wall of the vessel. Normally the wall of the vessel absorbs heat first; then heat is transferred to the liquid inside so the temperature of the outside surface needs to be in excess of the boiling point of liquid for the temperature inside the liquid volume to reach boiling point. These disadvantages can be overcome easily by applying microwave technique because when heating with microwave, vessel wall is transparent to microwave and solvent/reagent absorbs microwave energy directly. The direct in core heating

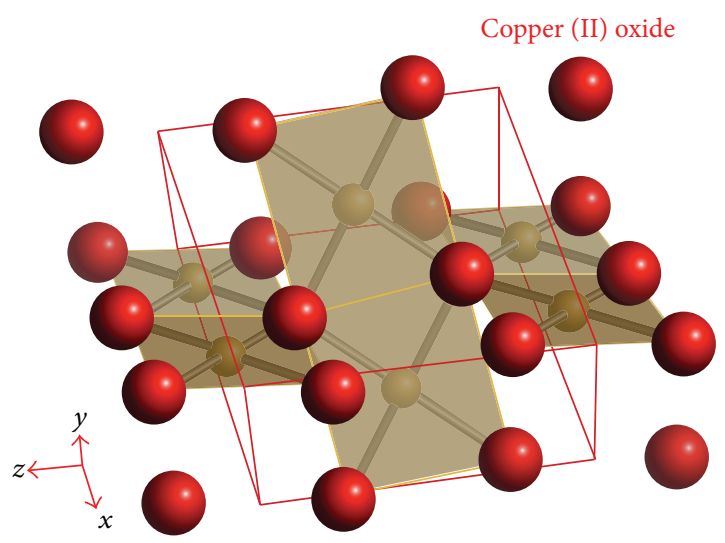

Figure 2: Crystal structure of $\mathrm{CuO}$.

and instant on-off pulse of heat lead to the formation of a homogenous temperature gradient and reduce the time reaction. These advances in turn produce smaller particles of uniform size and shape. By using microwave irradiation, different nanostructures of $\mathrm{CuO}$ of uniform size and shape could be prepared in a few minutes [16-18].

\section{Fundamental Properties}

3.1. Crystal Structure and Some Physics Constants. CuO crystal has monoclinic structure (Figure 2) and belongs to $\mathrm{C}^{6}{ }_{2 \mathrm{~h}}$ symmetry. Cupric oxide has four formula units per unit cell. The coordination number of copper atom is 4 , which means that it is linked to four oxygen neighbor atoms in an approximately square planar configuration in the (110) plane. In all crystallized solids, divalent copper surroundings are always very distorted by a strong Jahn-Teller effect which often leads to more stable square planar groups.

The $\mathrm{Cu}-\mathrm{O}$ bond lengths in this plane are 1.88 and $1.96 \AA$, respectively, which are larger than those in the cuprous oxide [23]. The next two $\mathrm{Cu}-\mathrm{O}$ bond lengths perpendicular to the plane are much greater, so an octahedral type of coordination can be ruled out. The $\mathrm{O}$ atom is coordinated to four $\mathrm{Cu}$ atoms in the form of a distorted tetrahedron. It is often accepted that the $\mathrm{CuO}$ has a mixture bonding of ionic and covalent bonding, even though the oxidation state of $\mathrm{Cu}$ in $\mathrm{CuO}$ is unquestionably $\mathrm{Cu}^{2+}$.

The lattice parameters of cupric oxide [24] are $a=$ $4.6837 \AA, b=3.4226 \AA, c=5.1288 \AA, \beta=99.54^{\circ}$, and $\alpha=\gamma=90^{\circ}$. Some other basic physics constants of $\mathrm{CuO}$ were also summarized in Table 2.

$\mathrm{X}$-ray diffraction is obviously the most common tool to study the crystal structure of materials and confirm the purity of the product. From X-ray diffraction pattern, the lattice constants, lattice strain, or particles size can be extracted following the Debye Sherrer formula. According to Aparna et al. [12], elastic strain calculated from XRD results shows that $\mathrm{CuO}$ nanoparticles smaller than $20 \mathrm{~nm}$ have high strain and greater particles have less strain. This phenomenon relates to the pressure different between the inside and outside of a curved surface, resulting from the surface tension. 
TABLE 2: Crystallographic properties of $\mathrm{CuO}$ and some physics constants of $\mathrm{CuO}$ [24].

\begin{tabular}{lc}
\hline Space group & C2/c (No. 15) \\
\hline & $a=4.6837 \AA$ \\
& $b=3.4226 \AA$ \\
Unit cell & $c=5.1288 \AA$ \\
& $\beta=99.54^{\circ}$ \\
& $\alpha=\gamma=90^{\circ}$ \\
Cell volume & $81.08 \AA^{3}$ \\
Cell content & $4 \mathrm{CuO}$ \\
Formula weight & 79.57 \\
Density & $6.515 \mathrm{~g} \mathrm{~cm}^{-3}$ \\
Distances & \\
Cu-O & $1.96 \AA$ \\
O-O & $2.62 \AA$ \\
Cu-Cu & $2.90 \AA$ \\
Melting point & $1201^{\circ} \mathrm{C}$ \\
\hline
\end{tabular}

Raman spectroscopy, which is a sensitive probe to the local atomic arrangements and vibrations of the materials, has been also widely used to investigate the microstructural nature of the nanosized materials in general and $\mathrm{CuO}$ nanomaterial in particular. Raman scattering also provides useful information about the structures and bonds of materials. Raman scattering could help to detect the existence of unintended phases such as $\mathrm{Cu}_{2} \mathrm{O}$ or $\mathrm{Cu}(\mathrm{OH})_{2}$ or show the crystallinity of the product. The space group of $\mathrm{CuO}$ is $\mathrm{C}^{6}{ }_{2 \mathrm{~h}}$ with two molecules per primitive cell so the zone center Raman active normal modes of $\mathrm{CuO}$ are $\Gamma_{\mathrm{RA}}=4 \mathrm{~A}_{\mathrm{u}}+5 \mathrm{~B}_{\mathrm{u}}+$ $\mathrm{A}_{\mathrm{g}}+2 \mathrm{~B}_{\mathrm{g}}$. Among these vibration modes, there are three acoustic modes $\left(A_{u}+2 B_{u}\right)$, six infrared active modes $\left(3 A_{u}\right.$ $\left.+3 \mathrm{~B}_{\mathrm{g}}\right)$, and three Raman active modes $\left(\mathrm{A}_{\mathrm{g}}+2 \mathrm{~B}_{\mathrm{g}}\right)$. Three well known bands of $\mathrm{CuO}$ are $\mathrm{A}_{\mathrm{g}}\left(296 \mathrm{~cm}^{-1}\right), \mathrm{B}_{\mathrm{g}}{ }^{(1)}\left(346 \mathrm{~cm}^{-1}\right)$, and $\mathrm{B}_{\mathrm{g}}{ }^{(2)}\left(631 \mathrm{~cm}^{-1}\right)$ [13]. Figure 3 shows Raman spectra of $\mathrm{CuO}$ nanostructures prepared by microwave irradiation method with three typical modes.

$\mathrm{Xu}$ et al. studied Raman spectra of $\mathrm{CuO}$ nanocrystals with different grain sizes at room temperature and high temperatures up to $873 \mathrm{~K}$ [25]. They reported that Raman intensity is related to the grain size. Samples of smaller grain size show stronger and sharper Raman peaks which also shift to smaller wavenumbers. The red shifts could be explained by the phonon confinement effect in nanometer size materials $[25,26]$.

It should be noted that crystal defects, of which number increases rapidly as the grain size decreases due to the large surface/volume ratio, could contribute significantly to Raman spectra as all of the three Raman modes in $\mathrm{CuO}$ relate only to the vibration of oxygen atoms as was pointed out by Irwin and Wei [27].

Apart from the three main vibration modes above, Wang et al. [28] reported multiphonon band of $\mathrm{CuO}$ nanostructures, which appears at wavenumber of $1130 \mathrm{~cm}^{-1}$ and relates to the inharmonic coupling between phonons in polar

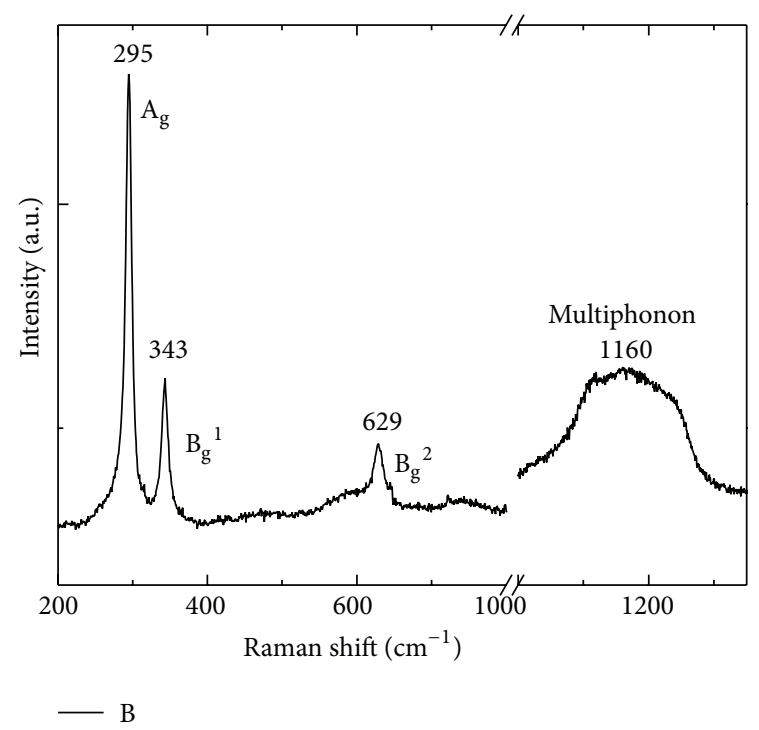

Figure 3: Raman spectra of $\mathrm{CuO}$ nanostructures prepared by microwave irradiation method (author's data).

solid. In particular, the multiphonon band $2 \mathrm{~B}_{\mathrm{g}}$ in $\mathrm{CuO}$ was suggested to be the stretching vibration in the $x^{2}-y^{2}$ plane, induced by the electronic density variation in this layer. The intensity of multiphonon Raman peak is much weaker than that of the one phonon band and varies with morphology and the size of the as prepared $\mathrm{CuO}$ nanostructures. The authors reported that the multiphonon band of the as prepared $\mathrm{CuO}$ nanostructures with belt-like morphology possesses higher intensity than that of the $\mathrm{CuO}$ nanostructures with shuttlelike morphology, while Raman intensity of multiphonon band of the shuttle-like morphology is higher than that of the $\mathrm{CuO}$ nanostructures with bamboo leaf-like morphology. The difference in the Raman intensity of different morphology was explained by anisotropy of different nanostructures. The electronic movement along the $x-y$ plane becomes significant in $x-y$ plane and promotes the intensity of $2 \mathrm{~B}_{\mathrm{g}}$ mode in belt-, shuttle-, and bamboo leaf-like nanostructures. Another explanation for the variation in the Raman intensity of this mode is the phonon-plasmon coupling due to high local density of anisotropic carriers in $\mathrm{CuO}$ nanostructures. The variation in the multiphonon intensity shows a finite size and crystallinity effect of $\mathrm{CuO}$ nanostructures.

3.2. Optical Properties. Compared with other properties such as electrical conductivity and field emission, optical property of $\mathrm{CuO}$ nanostructures has been much less investigated and discussed so far. As a $\mathrm{p}$ type semiconductor, a narrow bandgap of around $1.2 \mathrm{eV}$ was reported for bulk $\mathrm{CuO}$ [3]. In fact, reported values of bandgap for $\mathrm{CuO}$ were not in good agreement; for example, bandgap in the range of 1.56 and $1.85 \mathrm{eV}$ was reported for $\mathrm{CuO}$ thin films $[29,30]$. In addition, the variation of bandgap could also relate to quantum size effect in different $\mathrm{CuO}$ nanostructures $[31,32]$.

For nanomaterials, several methods could be applied to characterize the optical properties or to estimate the bandgap 
in particular. Among these methods, UV-vis absorption spectroscopy, as a nondestructing and quick technique, is one of the most convenient methods to reveal the energy structures and optical properties of semiconducting materials. The optical bandgap of semiconductor material can be calculated from the absorption spectra by using Tauc's relation [33]

$$
\alpha h v=\left(h v-E_{g}\right)^{n}
$$

where $h v$ is the energy of incident photon and $n$ is the exponent factor that determines the type of electronic transition causing the absorption and can take the values $1 / 2$ and 2 depending whether transition is direct or indirect, respectively. Bandgap is determined from the intercept of the straight line with the horizontal axis. By UV-vis studies, some groups have reported significant blue shift (up to $1.7 \mathrm{eV}$ ) [34] in the absorption edge compared with the bandgap of bulk material, which was explained by the quantum confinement effect in these nanostructures.

In literature, optical behavior of $\mathrm{CuO}$ nanomaterials has been mainly assessed by absorption techniques, while luminescence techniques, which are important tools to investigate electronic transitions in semiconductors-including band edge or near band edge transitions-have been seldom used. The low emission efficiency of $\mathrm{CuO}$ is the main reason for the lack of luminescence data for $\mathrm{CuO}$ nanomaterials; also the results on the origin of luminescence of $\mathrm{CuO}$ remain contradictory.

There are several photoluminescence bands generally reported for $\mathrm{CuO}$ nanostructures which expand from UV to near IR region; however the most frequent peaks fall in the region from 400 to $600 \mathrm{~nm}$. Generally, the deep level emission in $\mathrm{CuO}$ consists of a green emission at around $605 \mathrm{~nm}$ and a near-yellow emission at around $680 \mathrm{~nm}$. Though the origin of deep level emission in $\mathrm{CuO}$ is under debate, and little information is available on the $\mathrm{CuO}$ defect structure, the deep emissions are generally supposed to relate to defects in $\mathrm{CuO}$ nanomaterial. $\mathrm{CuO}$ is intrinsically a $\mathrm{p}$ type semiconductor due to the existence of $\mathrm{Cu}$ vacancies. However, recent theoretical calculations indicate that although $\mathrm{Cu}$ vacancies are the most stable defects in $\mathrm{CuO}$, they do not make any changes in the electronic structures of $\mathrm{CuO}$. Otherwise, oxygen vacancies or $\mathrm{O}_{\mathrm{Cu}}$ antisite defects are likely responsible for these emissions while their formation energy is not much different from formation energy of $\mathrm{Cu}$ vacancies [35]. The green emission is commonly assigned to the singly ionized oxygen vacancies; the yellow or red emission has been supposed to relate to the interstitial metal ion in the oxide. Therefore, the evolution of green and yellow bands in $\mathrm{CuO}$ is competitive with each other. The blue shift behavior of the near band edge transition in comparison with that of the bulk $\mathrm{CuO}$ in combination with the findings from UV-vis analysis was normally attributed to the enhancement of the quantum confinement effect resulting from the decrease in the dimensional structure and the size of the nanoparticles. One can also evaluate the concentration of structural defects by comparing the photoluminescence intensity ratio of near band edge emission to green deep level emission. This kind of assignment was applied by some groups. Vila et al. [36] observed luminescence bands centered at 1.33, 1.23, and $1.11 \mathrm{eV}$ in $\mathrm{CuO}$ nanomaterial and suggested that the emission with highest energy corresponds to near band edge transition in $\mathrm{CuO}$ while the two other emissions are most probably introduced by oxygen vacancies and oxygen on copper antisite defects $[35,37,38]$.

Besides emissions in visible or IR region, other authors announced emissions in the UV region. Santra et al. [29] observed the near band edge emission at $395 \mathrm{~nm}$ in the violet region. Aslani [39] reported near band edge emission at $300 \mathrm{~nm}$. Mageshwari and Sathvamoorthy [40] reported several photoluminescence peaks at 325, 339, and $356 \mathrm{~nm}$ and explained the difference photoluminescence emission peaks of $\mathrm{CuO}$ as agreed with earlier reports by various sizes and shapes of $\mathrm{CuO}$ nanostructures. This fact indicates that luminescence properties of $\mathrm{CuO}$ are strongly dependent on the morphology of the nanocrystals.

Gizhevskiǐ et al. [41] studied the influence of temperatures and annealing time during sample preparation on the photoluminescence properties of $\mathrm{CuO}$ nanocrystals and reported three main broad emission bands centered at about $305 \mathrm{~nm}$ $(4.07 \mathrm{eV}), 505 \mathrm{~nm}(2.46 \mathrm{eV})$, and $606 \mathrm{~nm}(2.05 \mathrm{eV})[4,14,39$, $42,43]$. The 2 nd band was attributed to band edge emission while the band at $600 \mathrm{~nm}$ region was also assigned to defect related states. The emission at the band edge contains several subpeaks due to the band edge emission from $\Gamma_{1}^{+}$to the new sublevels which might arise by the interaction of two excitons or the ${ }^{3} \mathrm{D}-{ }^{1} \mathrm{D}$ splitting in $\mathrm{Cu}^{+}\left(3 \mathrm{~d}^{9} 4 \mathrm{~s}^{2}\right)$ at $300 \mathrm{~K}$. PL intensities of the $305 \mathrm{~nm}(4.07 \mathrm{eV})$ band were seen to increase with the increasing temperature treatment and were explained by the enhancement of the crystallinity of the sample.

3.3. Magnetic Properties. As mentioned in the section of optical properties, photoluminescence and magnetic properties are aspects of least study for $\mathrm{CuO}$ nanomaterials; however $\mathrm{CuO}$ nanostructures showed interesting and unique magnetic properties so it is worth making a summary on this topic. $\mathrm{CuO}$, which is different from other antiferromagnetic transition metal monoxides such as $\mathrm{NiO}, \mathrm{MnO}$, and $\mathrm{CoO}$, shows magnetic order even above its Neel temperature.

Kimura et al. [44] reported that the ferromagnetic or antiferromagnetic ordering in $\mathrm{CuO}$ single crystal could be controlled by fine tuning the bond angle between in plane $\mathrm{Cu}-\mathrm{O}$ $\mathrm{Cu}$. Large bond angle $\mathrm{Cu}-\mathrm{O}-\mathrm{Cu}$ was believed to result in large super exchange interaction, favored for antiferromagnetism while spiral ordering in certain crystallographic directions favors a ferroelectric phase in the same material. Due to the complex dependence on temperature of spin structure, $\mathrm{CuO}$ normally shows two antiferromagnetic transitions at $213 \mathrm{~K}$ and $230 \mathrm{~K}$, respectively. The first Neel temperature related to commensurate to incommensurate transition, whereas the second one is attributed to incommensurate to paramagnetic transition.

A hysteresis loop or a bifurcation in FC-ZFC curves was reported by a few groups as evidences for ferromagnetism in $\mathrm{CuO}$ nanostructures [45]. For $\mathrm{CuO}$ nanomaterials, some reports showed that magnetic properties could vary, depending on size of the nanostructures. For example, Punnoose 
et al. [46] showed that susceptibility of $\mathrm{CuO}$ nanoparticles is inverse proportional to the particle size for particle smaller than $10 \mathrm{~nm}$. The magnetic behaviors of $\mathrm{CuO}$ nano particles larger than $10 \mathrm{~nm}$ are similar to bulk material. However, morphology of $\mathrm{CuO}$ nanostructures should play an important role as well, because other authors showed that ferromagnetism could also arise in nanosheets, nanoneedles, and so on of larger size $[47,48]$. Hysteresis loop of weak ferromagnetism was observed at $5 \mathrm{~K}$ in $\mathrm{CuO}$ nanosheets prepared by hydrothermal synthesis by the group of Zhao et al. [47]. Temperature dependence of magnetization showed Neel temperature of $\mathrm{CuO}$ nanosheets of $219 \mathrm{~K}$ while the FC and ZFC data show obviously maxima at about $40 \mathrm{~K}$, which probably corresponded to blocking temperatures. Below $40 \mathrm{~K}$, the magnetization increases rapidly in FC data which reconfirms the existence of weak ferromagnetism in $\mathrm{CuO}$ nanosheets. The influence of impurities such as $\mathrm{Fe}, \mathrm{Ni}$ at low content $(0.5 \%)$ was excluded as the most probable ferromagnetic material is $\mathrm{CuFe}_{2} \mathrm{O}_{4}$ but the magnetization of this phase is only half of as-measured magnetization of $\mathrm{CuO}$ nanosheets. The ferromagnetism resulted from the uncompensated spins on the surface of nanomaterials, which will be orientated under magnetic field and results in weak ferromagnetism as observed in $\mathrm{CuO}$ nanostructures. As the surface area of nanomaterials is much larger than that of bulk $\mathrm{CuO}$, the surface effect, which is in this case shown by the ferromagnetic property, becomes dominant and hence $\mathrm{CuO}$ nanomaterials will exhibit ferromagnetic property more clearly. This argument could explain the size and morphology dependence of the ferromagnetism of $\mathrm{CuO}$ nanostructures.

According to Bhalerao-Panajkar et al. [48], the core shell nature of their $\mathrm{CuO}$ nanoparticles with a ferromagnetic shell and antiferromagnetic core may be responsible for bifurcation of FC-ZFC curves because in pure antiferromagnetic or dominantly antiferromagnetic particles no bifurcation in FCZFC curves occurs.

The bifurcation in FC-ZFC could also arise due to the ferromagnetic nature of the shell supporting the core shell nature of the particles. Ferromagnetic/antiferromagnetic core shell structure was also supported by the asymmetry of the coercivity plot, which indicates the presence of an exchange field in core/shell system as suggested by other groups.

\section{Applications of $\mathrm{CuO}$ Nanoparticles}

$\mathrm{CuO}$ first attracted attention of chemists as a good catalyst in organic reactions but recently discovered applications of $\mathrm{CuO}$ such as high-Tc superconductors, gas sensors, solar cells, emitters, electronic cathode materials also make this material a hot topic for physicists and materials science engineers. Some of the most interesting applications of $\mathrm{CuO}$ nanomaterials are sensing, photocatalyst, and super capacitor that will be highlighted in this section.

4.1. Sensing Applications. It is surface conductivity that makes $\mathrm{CuO}$ an ideal material for semiconductor resistive gas sensor applications and in fact $\mathrm{CuO}$ nanomaterials were used for detection of many different compounds such as $\mathrm{CO}$, hydrogen cyanide, and glucose. As sensing properties closely relate to the chemical reaction on the surface of sensor, the specific area is a key factor to achieve high sensitivity sensor. Due to the high surface area/volume ratio, the sensing property of $\mathrm{CuO}$ nanomaterials was enhanced greatly. The shape of $\mathrm{CuO}$ nanostructures was also believed to affect significantly the sensing properties of $\mathrm{CuO}$ nanomaterial; for example, spherical crystals often show higher sensitivity than columnar one.

Aslani and Oroojpour[4] studied CO-sensing properties of different $\mathrm{CuO}$ nanoparticles prepared by solvothermal route as a function of morphology and size of nanoparticles. The results show that cloud like structures with high surface area/volume have higher response and detection limit than other morphologies. Yang et al. [5] also showed that the specific surface area of these $\mathrm{CuO}$ nanostructures plays an important role in the sensitivity for detecting $\mathrm{HCN}$. Both sides ( $5 \mathrm{~mm}$ in diameter) of a silver-coated quartz crystal microbalance $(\mathrm{QCM})$ resonator were covered with $\mathrm{CuO}$ nanostructures; the resonator was used as sensing probe in a quartz crystal resonator. The absorbance of HCN gas on sensor is indicated by the shift of resonant frequency. As specific area of $\mathrm{CuO}$ nanostructure used for coating the probe changes from $9.3 \mathrm{~m}^{2} / \mathrm{g}$ to $1.5 \mathrm{~m}^{2} / \mathrm{g}$, the sensitivity reduces from 2.26 to $0.31 \mathrm{~Hz} / \mu \mathrm{g}$. In both reports, the authors showed that the sensitivity of sensors depends not only on the surface area but also on the morphology of the nanostructure. The change in sensitivity of different nanostructures could be explained by the variation in the chemical reactivity of different crystal planes.

Glucose detection is another important application of $\mathrm{CuO}$ in sensing field. In conventional methods, glucose detection is based on the use of glucose oxidase which is an enzyme used in the sensor. This enzyme catalyzes the oxidation of glucose to gluconolactone and simultaneously produces $\mathrm{H}_{2} \mathrm{O}_{2}$. Glucose level is then evaluated by estimation from electrochemical response to the liberated $\mathrm{H}_{2} \mathrm{O}_{2}$. However, the main disadvantages of conventional methods are high cost and lack of enzyme stability, complicated immobilization procedures of enzyme, and the coexisting interferences in the biological fluids together with critical operating conditions. Most of those limitations could be solved by using $\mathrm{CuO}$ nanostructures as an alternative oxidase, where $\mathrm{CuO}$ nanomaterials act as catalyst to convert glucose into gluconolactone and finally to glucose acid. The better efficiency of the oxidized reaction in $\mathrm{CuO}$ based sensor resulted from high surface area, surface energy which enhanced electron transfer ability of $\mathrm{CuO}$ nanomaterials.

4.2. Supercapacitors and Electrodes for Lithium Ion Batteries. Pseudocapacitors also known as one type of supercapacitors have attracted significant attention of researcher as efficient energy storage devices with superior properties such as high power density, excellent reversibility, and long cycle life timedependent power, which are necessary properties of electronics portable devices. As the demand for high capacity energy storage in modern life was raised continuously, pseudocapacitors have become a hot topic recently. Among transition 
metal oxides which are considered as ideal electrode materials for pseudocapacitors, $\mathrm{CuO}$ is a really promising candidate for its abundant resources, environmental compatibility, cost effectiveness, and favorable pseudocapacitive characteristics.

It was found that the morphology and particle size of $\mathrm{CuO}$ remarkably affected its specific capacity. Cauliflower like, nanobelt-shaped, and feather-like $\mathrm{CuO}$ nanocrystals were synthesized by the chemical deposition method by group of $\mathrm{H}$. Zhang and $M$. Zhang [49]. According to the authors, morphologies of the $\mathrm{CuO}$ nanostructures can influence the electrochemical properties significantly. The electrochemical properties of $\mathrm{CuO}$ as electrode material were enhanced by the improving of morphology. Cauliflower-like $\mathrm{CuO}$ exhibited a higher specific capacitance $\left(116.9 \mathrm{~F} \mathrm{~g}^{-1}\right)$ than nanobelt-shaped and feather-like $\mathrm{CuO}$ and also showed good reversibility. Specific capacitance of cauliflower-like $\mathrm{CuO}$ $\left(115.3 \mathrm{~F} \mathrm{~g}^{-1}\right)$ was $343.5 \%$ higher than $\mathrm{CuO}$ bought $\left(26 \mathrm{~F} \mathrm{~g}^{-1}\right)$ at $5 \mathrm{~mA} \mathrm{~cm}^{-2}$. The $\mathrm{CuO}$ cauliflower-like exhibited a higher utilization efficiency and better property for electrolyte diffusion than the feather-like and nanobelts structures. The increasing order of the specific capacitance was consistent with increasing sequence of $\mathrm{CuO}$ specific surface area, indicating that the highly mesoporous structure and high specific surface area of the electrode facilitate the ions to transfer into the porous structure more easily which would lead to more redox faradic reactions and surface adsorption of electrolyte cations.

$\mathrm{CuO}$ nanomaterials could substitute for graphite anode in LIBs due to its superiorities such as high theoretical capacity (670 $\left.\mathrm{mAhg}^{-1}\right)$, improved safety, low cost and environmental benignity. However, it also suffers very rapid capacity decay caused by huge and uneven volume variations (around 174\%) during the lithium uptake/releasing process. One possible approach to improve the electrochemical performance of $\mathrm{CuO}$ materials is to use well-configured nanostructures ranging from zero-dimensional nanoparticles to multidimensional assemblies. In these nanostructures, not only lithium diffuses much easier, but also the strain associated with lithium uptake could be well accommodated, leading to better electrochemical performance. Wang et al. [50] successfully prepared nanorods and nanosheets on a $\mathrm{Cu}$ substrate. The unique nanostructural features endower them excellent electrochemical performance with high capacities of 450$650 \mathrm{mAh} \mathrm{g}^{-1}$ at $0.5-2 \mathrm{C}$ and almost $100 \%$ capacity retention over 100 cycles after the second cycle. Recently composite material of $\mathrm{CuO}$ nanomaterial was developed to further increase the capacities of LIBs. Rai et al. [51] successfully used $\mathrm{CuO} /$ reduced graphene oxide nanocomposite as anode materials for lithium ion batteries. The initial discharge capacity of the pure $\mathrm{CuO}$ nanoparticles and their nanocomposite is $785.2 \mathrm{mAh} \mathrm{g}^{-1}$ and $1043.3 \mathrm{mAhg}^{-1}$ with reversible capacity retention of $392.1 \mathrm{mAh} \mathrm{g}^{-1}$ and $516.4 \mathrm{mAh} \mathrm{g}^{-1}$ after 45 cycles, respectively.

4.3. Photocatalyst and Solar Energy Conversion. Water pollution due to organic wastage from industry production has become a serious problem in the world today. Most of organic compounds in waste water are toxic and cannot be decomposed naturally so they need to be treated with care before disposal. Water treatment using semiconductor catalysts under solar UV or visible light seems to be the most effective way as it has shown that this method could be employed to totally decompose many different organic compounds into biodegradable without complex technologies. $\mathrm{CuO}$ is a promising candidate due to low cost and abundance.

As a $\mathrm{p}$ type semiconductor of narrow bandgap in visible region, $\mathrm{CuO}$ is expected to be a good material for application in photocatalyst and solar energy conversion. However, some groups reported that $\mathrm{CuO}$ shows almost no or very little photocatalyst properties under visible light. Adding some amount of $\mathrm{H}_{2} \mathrm{O}_{2}$ could help to greatly improve the photocatalyst efficiency under visible light. Yecheskel et al. study the degradation of brominated flame retardants by copper oxide nanoparticles and saw that adding an amount of $\mathrm{H}_{2} \mathrm{O}_{2}$ enhances the photocatalyst properties of $\mathrm{CuO}$ nanoparticles [1]. They also showed that the interaction of $\mathrm{CuO}$ nanoparticles with $\mathrm{H}_{2} \mathrm{O}_{2}$ results in an electron spin resonance spectrum similar to spectrum of $\mathrm{Cu}^{2+}$ ion. This fact might indicate a release of $\mathrm{Cu}^{2+}$ ion to the solution or changes in the electron configuration of $\mathrm{CuO}$ nanoparticles in the solid phase. Based on these effects, the authors suggested that $\mathrm{H}_{2} \mathrm{O}_{2}$ may have a role in the activation of $\mathrm{CuO}$ catalyst besides being an oxidative agent. It is noteworthy that photocatalyst properties also show dependence on size and shape of $\mathrm{CuO}$ nanostructures which again can be explained by the enhancement due to large surface area as well as the anisotropic of single crystals nanostructures of $\mathrm{CuO}$, meaning that the photocatalyst of different crystal plane in $\mathrm{CuO}$ could be different.

$\mathrm{CuO}$ could also be good candidate in solar energy conversion due to many properties: high absorption coefficient, narrow bandgap in visible region which is expected to give high conversion efficiency, being nontoxic, stability, good electrical conductance, simple manufacture process, and so on. A more direct way to convert solar energy to electricity is to use $\mathrm{CuO}$ as absorber in solar cell. Efficiency of solar cell based on $\mathrm{CuO}$ is far lower than efficiency of leading chalcogenide system such as CIS or CIGS, but due to its low cost, abundant resource, and simple preparation process it was shown that efficiency of only several percents in cell based on $\mathrm{CuO}$ is good enough to make commercial solar cells. Different from its counterpart $\mathrm{Cu}_{2} \mathrm{O}, \mathrm{CuO}$ is used less for solar cell as the achieved efficiency for $\mathrm{Cu}_{2} \mathrm{O}$ is higher. Number of reports on $\mathrm{CuO}$ solar cell is rare but recent results show very promising achievement, which shows that further development of $\mathrm{CuO}$ nanomaterials based solar cell has a bright future. Kidowaki et al. [52] prepared solar cells based on $\mathrm{CuO}$ nanoparticles/C60 junction which provided efficiency $\eta$ of $1.8 \times 10^{-6} \%$, fill factor of $0.25, J_{\text {sc }}$ of $0.18 \times$ $10^{-3} \mathrm{~mA} \mathrm{~cm}^{-2}$ and $V_{\text {oc }}$ of $0.04 \mathrm{~V}$. A crystallite size of $\mathrm{CuO}$ was determined to be $3.4 \mathrm{~nm}$, and higher crystallinity of $\mathrm{CuO}$ would increase the efficiency of the $\mathrm{CuO} / \mathrm{C} 60$ solar cells. Or more recently, using solvothermal method, Chandrasekaran [53] prepared $\mathrm{CuO}$ nanoparticles and used the product to make a solar cell with efficiency of $0.863 \%$, which is compared with other reported values $[15,54,55]$. Up to now, the record efficiency of solar cell based on copper oxide is about $2 \%$, 
while the theoretical value is about $20 \%$, so efficiency of several percents is obviously achievable.

$\mathrm{CuO}$ nanomaterials could also be used as good substitution for expensive noble metal cathode in dye solar cell. This topic was first introduced by Anandan et al. [56] in 2005 and the optimal power conversion efficiency when using $\mathrm{CuO}$ nanorods as electrode was $0.29 \%$ compared with $1.23 \%$ when using $\mathrm{Pt}$ as electrode in the same condition. By using $\mathrm{CuO}$ nanoneedles of higher surface active area, Liu et al. [57] obtained an efficiency of $1.12 \%$, for $\mathrm{TiO}_{2}$ based dye solar cell. This result shows that nanomaterials of $\mathrm{CuO}$ could replace well Pt electrodes and can even give better efficiency under optimization process.

4.4. Field Emission Effect. Field emission displays are now in a more dominant position in the market compared with CRT displays because of their advanced properties such as high brightness, good color rendition, short response time, and low power consumption. Among the various nanomaterials studied for field emission applications, 1D nanostructures of $\mathrm{CuO}$ emerged as very promising field emitters because of some advantages: low turn-on field, high current density, and low fabrication cost [58-62].

Liu et al. [58] investigated the field emission properties of an individual $\mathrm{CuO}$ nanoneedle by in situ microscopy. The authors showed that individual nanoneedle possesses good field emission properties, such as low turn-on field of $5.3 \mathrm{~V} / \mu \mathrm{m}$, high maximum current of $1.08 \mu \mathrm{A}$ at $9.7 \mathrm{~V} / \mu \mathrm{m}$. The field emission properties of the single $\mathrm{CuO}$ nanoneedle and $\mathrm{CuO}$ nanoneedle's film arrays are also compared and the results showed that the screening effect played a key role in the field emission properties.

$\mathrm{Hu}$ et al. [60] used a simple method of direct heating of bulk copper plates in air to obtain $\mathrm{CuO}$ nanowire films on a large scale. The length and density of nanowires could be controlled by growth temperature and growth time. The as produced $\mathrm{CuO}$ nanowires have high density, good preferred orientation, and sharp tip, which is very beneficial to field emission. Field emission measurements showed that $\mathrm{CuO}$ nanowires have a low turn-on field of $3.5-4.5 \mathrm{~V} / \mu \mathrm{m}^{-1}$ and a large current density of $0.45 \mathrm{~mA} \mathrm{~cm}^{-2}$ under an applied

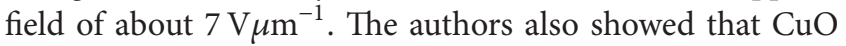
nanowires having large length/radius ratio can effectively improve the local field, which enhance field emission. Zhu et al. [61] prepared some different $\mathrm{CuO}$ nanostructures by solution method. By varying the oxidant concentration, the authors can modulate the morphology of the nanoproducts from nanorod to nanotubes. The tip morphologies of $\mathrm{CuO}$ nanostructures were found to be crucial for the field electron emission, and the nanorods with needle-like tips showed superior emission properties with a turn-on field of $3.5 \mathrm{~V} / \mu \mathrm{m}$ and a field enhancement factor of 2107 , compared to other structures.

Apart from improving the field emission efficiency by optimizing the aspect ratio (length/diameter) of $1 \mathrm{D}$ nanostructures, some other methods were also utilized to enhance the field emission current. Wang and $\mathrm{Li}$ [62] found that laser irradiation could effectively enhance the field emission current of $\mathrm{CuO}$ nanowire arrays. The effects of laser intensity, wavelength, emission current, and working vacuum on the enhancement have been investigated in detail. Among these factors, the contribution from extra excited electrons, which increases the number of electrons in conduction band of $\mathrm{CuO}$ for subsequent tunneling, is dominant. The observed laser induced enhancement in field emission current is attributed to the interplay of two factors, namely, laser induced electron transition to excited states and surface oxygen desorption. Based on the idea of light induced field emission of their work, new vacuum nanodevices of $\mathrm{CuO}$ nanowires such as photodetectors or switches could be developed in the future. Another example is the work of Maji et al.[34], where the authors also prepared $\mathrm{CuO}$ nanowire arrays by thermal oxidation. In order to improve the field emission properties of $\mathrm{CuO}$ nanowires they coated a $\mathrm{ZnO}$ layer on a $\mathrm{Cu}$ substrate before the thermal oxidation process. The $\mathrm{ZnO}$ layer was deposited by immersing a $\mathrm{Cu}$ foil into an aqueous solution of zinc nitrate and hexamethylenetetramine at $95^{\circ} \mathrm{C}$ for several hours. The turn-on field of the $\mathrm{ZnO}$-coated $\mathrm{CuO}$ nanowire array was $0.85 \mathrm{~V} / \mu \mathrm{m}$ compared with turn-on field $6.5 \mathrm{~V} / \mu \mathrm{m}$ of $\mathrm{CuO}$ nanowires without $\mathrm{ZnO}$ coating layer at the same current density of $10 \mu \mathrm{A} / \mathrm{cm}^{2}$. The authors suggested that in addition to the enlarged nanowire density and aspect ratio, crack elimination may be the reason for the enhancement of field emission properties.

\section{Conclusion}

In conclusion, $\mathrm{CuO}$ nanostructures have been widely studied and are receiving more and more attention from material scientists and engineers recently because of their interesting properties and potential applications in various fields. In this study, we make a summary on the influences of different factors of synthesis process, some unique properties, and some promising applications of $\mathrm{CuO}$ nanostructures. We focus on the some chemical synthetic strategies along with associated influence of basic factors of synthesizing process for $\mathrm{CuO}$ nanostructures, as well as their interesting fundamental properties, and interesting applications. Understanding the synthesizing process as well as the characteristics of $\mathrm{CuO}$ nanostructures is fundamental for further purposes to realize application of $\mathrm{CuO}$ nanostructures in daily life and technology. Some unique properties of $\mathrm{CuO}$ nanostructures which make $\mathrm{CuO}$ different from other transition metal oxides were also summarized and highlighted. Some potential applications based on $\mathrm{CuO}$ nanostructures are also presented.

Although encouraging developments and fascinating achievements in $\mathrm{CuO}$ nanostructures have been obtained as overviewed in this paper, better understanding for controlling morphology, structures, and properties of cupric oxide nanostructures and finding ways to take advantages of these interesting properties of such nanostructures still require much effort from scientists but also bring in opportunities for further development.

\section{Conflict of Interests}

The authors declare that there is no conflict of interests regarding the publication of this paper. 


\section{Acknowledgment}

The authors would like to thank Hanoi University of Mining and Geology for supporting finance.

\section{References}

[1] Y. Yecheskel, I. Dror, and B. Berkowitz, "Catalytic degradation of brominated flame retardants by copper oxide nanoparticles," Chemosphere, vol. 93, no. 1, pp. 172-177, 2013.

[2] Q. Zhang, K. Zhang, D. Xu et al., "CuO nanostructures: synthesis, characterization, growth mechanisms, fundamental properties, and applications," Progress in Materials Science, vol. 60, no. 1, pp. 208-237, 2014.

[3] P. Raksa, A. Gardchareon, T. Chairuangsri, P. Mangkorntong, N. Mangkorntong, and S. Choopun, "Ethanol sensing properties of $\mathrm{CuO}$ nanowires prepared by an oxidation reaction," Ceramics International, vol. 35, no. 2, pp. 649-652, 2009.

[4] A. Aslani and V. Oroojpour, "CO gas sensing of $\mathrm{CuO}$ nanostructures, synthesized by an assisted solvothermal wet chemical route," Physica B: Condensed Matter, vol. 406, no. 2, pp. 144-149, 2011.

[5] M. Yang, J. He, X. Hu, C. Yan, and Z. Cheng, "CuO nanostructures as quartz crystal microbalance sensing layers for detection of trace hydrogen cyanide gas," Environmental Science and Technology, vol. 45, no. 14, pp. 6088-6094, 2011.

[6] Y. Li, J. Liang, Z. Tao, and J. Chen, "CuO particles and plates: synthesis and gas-sensor application," Materials Research Bulletin, vol. 43, no. 8-9, pp. 2380-2385, 2008.

[7] X. Wang and X. Xu, "Thermal conductivity of nanoparticle-fluid mixture," Journal of Thermophysics and Heat Transfer, vol. 13, no. 4, pp. 474-480, 1999.

[8] S. Ishio, T. Narisawa, S. Takahashi et al., " $L 1_{0}$ FePt thin films with $\left[\begin{array}{lll}0 & 0 & 1\end{array}\right]$ crystalline growth fabricated by $\mathrm{SiO}_{2}$ addition-rapid thermal annealing and dot patterning of the films," Journal of Magnetism and Magnetic Materials, vol. 324, no. 3, pp. 295-302, 2012.

[9] V. Kumar, S. Masudy-Panah, C. C. Tan, T. K. S. Wong, D. Z. Chi, and G. K. Dalapati, "Copper oxide based low cost thin film solar cells," in Proceedings of the IEEE 5th International Nanoelectronics Conference (INEC '13), pp. 443-445, January 2013.

[10] X. Liu, Z. Jiang, J. Li, Z. Zhang, and L. Ren, "Super-hydrophobic property of nano-sized cupric oxide films," Surface and Coatings Technology, vol. 204, no. 20, pp. 3200-3204, 2010.

[11] X.-D. Yang, L.-L. Jiang, C.-J. Mao, H.-L. Niu, J.-M. Song, and S.Y. Zhang, "Sonochemical synthesis and nonlinear optical property of $\mathrm{CuO}$ hierarchical superstructures," Materials Letters, vol. 115, pp. 121-124, 2014.

[12] Y. Aparna, K. V. E. Rao, and P. S. Subbarao, "Synthesis and characterization of $\mathrm{CuO}$ nano particles by novel sol-gel method," in Proceedings of the 2nd International Conference on Environment Science and Biotechnology, 2012.

[13] M. A. Dar, Q. Ahsanulhaq, Y. S. Kim, J. M. Sohn, W. B. Kim, and H. S. Shin, "Versatile synthesis of rectangular shaped nanobatlike $\mathrm{CuO}$ nanostructures by hydrothermal method; structural properties and growth mechanism," Applied Surface Science, vol. 255, no. 12, pp. 6279-6284, 2009.

[14] B. Toboonsung and P. Singjai, "Formation of $\mathrm{CuO}$ nanorods and their bundles by an electrochemical dissolution and deposition process," Journal of Alloys and Compounds, vol. 509, no. 10, pp. 4132-4137, 2011.
[15] K. Han and M. Tao, "Electrochemically deposited p-n homojunction cuprous oxide solar cells," Solar Energy Materials and Solar Cells, vol. 93, no. 1, pp. 153-157, 2009.

[16] W.-W. Wang, Y.-J. Zhu, G.-F. Cheng, and Y.-H. Huang, "Microwave-assisted synthesis of cupric oxide nanosheets and nanowhiskers," Materials Letters, vol. 60, no. 5, pp. 609-612, 2006.

[17] X. Xu, M. Zhang, J. Feng, and M. Zhang, "Shape-controlled synthesis of single-crystalline cupric oxide by microwave heating using an ionic liquid," Materials Letters, vol. 62, no. 17-18, pp. 2787-2790, 2008.

[18] L. Guo, F. Tong, H. Liu, H. Yang, and J. Li, "Shape-controlled synthesis of self-assembly cubic $\mathrm{CuO}$ nanostructures by microwave," Materials Letters, vol. 71, pp. 32-35, 2012.

[19] Z. Hu, G. Oskam, and P. C. Searson, "Influence of solvent on the growth of ZnO nanoparticles," Journal of Colloid and Interface Science, vol. 263, no. 2, pp. 454-460, 2003.

[20] S. Leekumjorn, S. Gullapalli, and M. S. Wong, "Understanding the solvent polarity effects on surfactant-capped nanoparticles," Journal of Physical Chemistry B, vol. 116, no. 43, pp. 13063-13070, 2012.

[21] L. Sun, Z. Zhang, Z. Wang, Z. Wu, and H. Dang, "Synthesis and characterization of $\mathrm{CuO}$ nanoparticles from liquid ammonia," Materials Research Bulletin, vol. 40, no. 6, pp. 1024-1027, 2005.

[22] B. V. Derjaguin, N. V. Churaev, and V. M. Muller, Surface Forces, 1987.

[23] W. Y. Ching, Y.-N. Xu, and K. W. Wong, "Ground-state and optical properties of $\mathrm{Cu}_{2} \mathrm{O}$ and $\mathrm{CuO}$ crystals," Physical Review $B$, vol. 40, no. 11, pp. 7684-7695, 1989.

[24] Y. Cudennec and A. Lecerf, "The transformation of $\mathrm{Cu}(\mathrm{OH})_{2}$ into $\mathrm{CuO}$, revisited," Solid State Sciences, vol. 5, no. 11-12, pp. 1471-1474, 2003.

[25] J. F. Xu, W. Ji, Z. X. Shen et al., "Raman spectra of CuO nanocrystals," Journal of Raman Spectroscopy, vol. 30, no. 5, pp. 413-415, 1999.

[26] M. Rashad, M. Rüsing, G. Berth, K. Lischka, and A. Pawlis, " $\mathrm{CuO}$ and $\mathrm{Co}_{3} \mathrm{O}_{4}$ nanoparticles: synthesis, characterizations, and raman spectroscopy," Journal of Nanomaterials, vol. 2013, Article ID 714853, 6 pages, 2013.

[27] J. C. Irwin and T. Wei, "Raman scattering investigation of $\mathrm{Cu}^{18} \mathrm{O}$," Journal of Physics: Condensed Matter, vol. 3, no. 3, pp. 299-306, 1991.

[28] W. Wang, Q. Zhou, X. Fei et al., "Synthesis of $\mathrm{CuO}$ nanoand micro-structures and their Raman spectroscopic studies," CrystEngComm, vol. 12, no. 7, pp. 2232-2237, 2010.

[29] K. Santra, C. K. Sarkar, M. K. Mukherjee, and B. Ghosh, "Copper oxide thin films grown by plasma evaporation method," Thin Solid Films, vol. 213, no. 2, pp. 226-229, 1992.

[30] S. Cho, "Optical and electrical properties of $\mathrm{CuO}$ thin films deposited at several growth temperatures by reactive RF magnetron sputtering," Metals and Materials International, vol. 19, no. 6, pp. 1327-1331, 2013.

[31] H.-H. Lin, C.-Y. Wang, H. C. Shih, J.-M. Chen, and C.-T. Hsieh, "Characterizing well-ordered $\mathrm{CuO}$ nanofibrils synthesized through gas-solid reactions," Journal of Applied Physics, vol. 95, no. 10, pp. 5889-5895, 2004.

[32] M. Kaur, K. P. Muthe, S. K. Despande et al., "Growth and branching of $\mathrm{CuO}$ nanowires by thermal oxidation of copper," Journal of Crystal Growth, vol. 289, no. 2, pp. 670-675, 2006.

[33] J. Tauc, R. Grigorovici, and A. Vancu, "Optical properties and electronic structure of amorphous germanium," Physica Status Solidi, vol. 15, pp. 627-637, 1966. 
[34] S. K. Maji, N. Mukherjee, A. Mondal, B. Adhikary, and B. Karmakar, "Chemical synthesis of mesoporous $\mathrm{CuO}$ from a single precursor: structural, optical and electrical properties," Journal of Solid State Chemistry, vol. 183, no. 8, pp. 1900-1904, 2010.

[35] D. Wu, Q. Zhang, and M. Tao, "LSDA+U study of cupric oxide: Electronic structure and native point defects," Physical Review B-Condensed Matter and Materials Physics, vol. 73, no. 23, Article ID 235206, 2006.

[36] M. Vila, C. Diaz-Guerra, and J. Piqueras, "Optical and magnetic properties of $\mathrm{CuO}$ nanowires grown by thermal oxidation," Journal of Physics D-Applied Physics, vol. 43, no. 13, pp. 135403135409, 2010.

[37] C. Carel, M. Mouallem-Bahout, and J. Gaudé, "Re-examination of the non-stoichiometry and defect structure of copper(II) oxide or tenorite, $\mathrm{Cu}_{1 \pm z} \mathrm{O}$ or $\mathrm{CuO}_{1 \pm \varepsilon}$ : A short review," Solid State Ionics, vol. 117, no. 1-2, pp. 47-55, 1999.

[38] Y. K. Jeong and G. M. Choi, "Nonstoichiometry and electrical conduction of CuO," Journal of Physics and Chemistry of Solids, vol. 57, no. 1, pp. 81-84, 1996.

[39] A. Aslani, "Controlling the morphology and size of $\mathrm{CuO}$ nanostructures with synthesis by solvo/hydrothermal method without any additives," Physica B: Condensed Matter, vol. 406, no. 2, pp. 150-154, 2011.

[40] K. Mageshwari and R. Sathyamoorthy, "Flower-shaped $\mathrm{CuO}$ nanostructures: synthesis, characterization and antimicrobial activity," Journal of Materials Science \& Technology, vol. 29, no. 10, pp. 909-914, 2013.

[41] B. A. Gizhevskiǐ, Y. P. Sukhorukov, A. S. Moskvin et al., "Anomalies in the optical properties of nanocrystalline copper oxides $\mathrm{CuO}$ and $\mathrm{Cu}_{2} \mathrm{O}$ near the fundamental absorption edge," Journal of Experimental and Theoretical Physics, vol. 102, no. 2, pp. 297302, 2006.

[42] C. Jin, K. Baek, S. Park, H. W. Kim, W. I. Lee, and C. Lee, "Influence of $\mathrm{SnO}_{2}$ coating and thermal annealing on the structure and luminescence properties of $\mathrm{CuO}$ nanorods," Solid State Communications, vol. 150, no. 37-38, pp. 1812-1817, 2010.

[43] S.-S. Chang, H.-J. Lee, and H. J. Park, "Photoluminescence properties of spark-processed $\mathrm{CuO}$," Ceramics International, vol. 31, no. 3, pp. 411-415, 2005.

[44] T. Kimura, Y. Sekio, H. Nakamura, T. Siegrist, and A. P. Ramirez, "Cupric oxide as an induced-multiferroic with high-TC," Nature Materials, vol. 7, no. 4, pp. 291-294, 2008.

[45] V. Bisht, K. P. Rajeev, and S. Banerjee, "Anomalous magnetic behavior of $\mathrm{CuO}$ nanoparticles," Solid State Communications, vol. 150, no. 17-18, pp. 884-887, 2010.

[46] A. Punnoose, H. Magnone, M. S. Seehra, and J. Bonevich, "Bulk to nanoscale magnetism and exchange bias in $\mathrm{CuO}$ nanoparticles," Physical Review B-Condensed Matter and Materials Physics, vol. 64, no. 17, Article ID 174420, 2001.

[47] J. G. Zhao, S. J. Liu, S. H. Yang, and S. G. Yang, "Hydrothermal synthesis and ferromagnetism of $\mathrm{CuO}$ nanosheets," Applied Surface Science, vol. 257, no. 22, pp. 9678-9681, 2011.

[48] R. S. Bhalerao-Panajkar, M. M. Shirolkar, R. Das, T. Maity, P. Poddar, and S. K. Kulkarni, "Investigations of magnetic and dielectric properties of cupric oxide nanoparticles," Solid State Communications, vol. 151, no. 1, pp. 55-60, 2011.

[49] H. Zhang and M. Zhang, "Synthesis of $\mathrm{CuO}$ nanocrystalline and their application as electrode materials for capacitors," Materials Chemistry and Physics, vol. 108, no. 2-3, pp. 184-187, 2008.

[50] Z. Wang, F. Su, S. Madhavi, and X. W. Lou, "CuO nanostructures supported on $\mathrm{Cu}$ substrate as integrated electrodes for highly reversible lithium storage," Nanoscale, vol. 3, no. 4, pp. 16181623, 2011.

[51] A. K. Rai, L. T. Anh, J. Gim et al., "Facile approach to synthesize $\mathrm{CuO} /$ reduced graphene oxide nanocomposite as anode materials for lithium-ion battery," Journal of Power Sources, vol. 244, pp. 435-441, 2013.

[52] H. Kidowaki, T. Oku, T. Akiyama, A. Suzuki, B. Jeyadevan, and J. Cuya, "Fabrication and characterization of CuO-based solar cells," Journal of Materials Science Research, vol. 1, no. 1, pp. 138143, 2012.

[53] S. Chandrasekaran, "A novel single step synthesis, high efficiency and cost effective photovoltaic applications of oxidized copper nano particles," Solar Energy Materials and Solar Cells, vol. 109, pp. 220-226, 2013.

[54] A. Y. Oral, E. Menşur, M. H. Aslan, and E. Başaran, “The preparation of copper(II) oxide thin films and the study of their microstructures and optical properties," Materials Chemistry and Physics, vol. 83, no. 1, pp. 140-144, 2004.

[55] W. Septina, S. Ikeda, M. A. Khan et al., "Potentiostatic electrodeposition of cuprous oxide thin films for photovoltaic applications," Electrochimica Acta, vol. 56, no. 13, pp. 4882-4888, 2011.

[56] S. Anandan, X. Wen, and S. Yang, "Room temperature growth of $\mathrm{CuO}$ nanorod arrays on copper and their application as a cathode in dye-sensitized solar cells," Materials Chemistry and Physics, vol. 93, no. 1, pp. 35-40, 2005.

[57] Y. Liu, L. Liao, J. Li, and C. Pan, "From copper nanocrystalline to $\mathrm{CuO}$ nanoneedle array: synthesis, growth mechanism, and properties," Journal of Physical Chemistry C, vol. 111, no. 13, pp. 5050-5056, 2007.

[58] Y. Liu, L. Zhong, Z. Peng, Y. Song, and W. Chen, "Field emission properties of one-dimensional single $\mathrm{CuO}$ nanoneedle by in situ microscopy," Journal of Materials Science, vol. 45, no. 14, pp. 3791-3796, 2010.

[59] Y. W. Zhu, T. Yu, F. C. Cheong et al., "Large-scale synthesis and field emission properties of vertically oriented $\mathrm{CuO}$ nanowire films," Nanotechnology, vol. 16, no. 1, pp. 88-92, 2005.

[60] L. Hu, D. Zhang, H. Hu, and T. Guo, "Field electron emission from structure-controlled one-dimensional $\mathrm{CuO}$ arrays synthesized by wet chemical process," Journal of Semiconductors, vol. 35, no. 7, Article ID 073003, pp. 1-4, 2014.

[61] Y. W. Zhu, C. H. Sow, and J. T. L. Thong, "Enhanced field emission from $\mathrm{CuO}$ nanowire arrays by in situ laser irradiation," Journal of Applied Physics, vol. 102, Article ID 114302, 2007.

[62] R.-C. Wang and C.-H. Li, "Improved morphologies and enhanced field emissions of $\mathrm{CuO}$ nanoneedle arrays by heating zno coated copper foils," Crystal Growth and Design, vol. 9, no. 5, pp. 2229-2234, 2009.

[63] D. T. Gazioğlu, F. Dumludağ, and A. Altindal, "Characterization of doped and undoped CuO nanoparticles," in Proceedings of the 7th International Conference of the Balkan Physical Union, Organized by the Hellenic Physical Society with the Cooperation of the Physics Departments of Greek Universities, vol. 1203 of AIP Conference Proceedings, pp. 456-460, 2010.

[64] A. El-Trass, H. Elshamy, I. El-Mehasseb, and M. El-Kemary, "CuO nanoparticles: synthesis, characterization, optical properties and interaction with amino acids," Applied Surface Science, vol. 258, no. 7, pp. 2997-3001, 2012.

[65] R. Etefagh, E. Azhir, and N. Shahtahmasebi, "Synthesis of CuO nanoparticles and fabrication of nanostructural layer biosensors for detecting Aspergillus niger fungi," Scientia Iranica, vol. 20, no. 3, pp. 1055-1058, 2013. 
[66] Y. Aparna, K. V. Enkateswara Rao, and P. Srinivasa Subbarao, "Synthesis and characterization of $\mathrm{CuO}$ nano particles by novel sol-gel method," in Proceedings of the 2nd International Conference on Environment Science and Biotechnology (IPCBEE '12), vol. 48, 2012.

[67] J. Zhu, H. Bi, Y. Wang, X. Wang, X. Yang, and L. Lu, "Synthesis of flower-like $\mathrm{CuO}$ nanostructures via a simple hydrolysis route," Materials Letters, vol. 61, no. 30, pp. 5236-5238, 2007.

[68] Z.-S. Hong, Y. Cao, and J.-F. Deng, "A convenient alcohothermal approach for low temperature synthesis of $\mathrm{CuO}$ nanoparticles," Materials Letters, vol. 52, no. 1-2, pp. 34-38, 2002.

[69] M. Zhang, X. Xu, and M. Zhang, "Hydrothermal synthesis of sheaf-like $\mathrm{CuO}$ via ionic liquids," Materials Letters, vol. 62, no. 3, pp. 385-388, 2008.

[70] C.-C. Li and M.-H. Chang, "Colloidal stability of $\mathrm{CuO}$ nanoparticles in alkanes via oleate modifications," Materials Letters, vol. 58, no. 30, pp. 3903-3907, 2004.

[71] Z. Cheng, J. Xu, H. Zhong, X. Chu, and J. Song, "Hydrogen peroxide-assisted hydrothermal synthesis of hierarchical $\mathrm{CuO}$ flower-like nanostructures," Materials Letters, vol. 65, no. 13, pp. 2047-2050, 2011.

[72] S. G. Rejith and C. Krishnan, "Optical, thermal and magnetic studies on zinc-doped copper oxide nanoparticles," Materials Letters, vol. 106, pp. 87-89, 2013. 

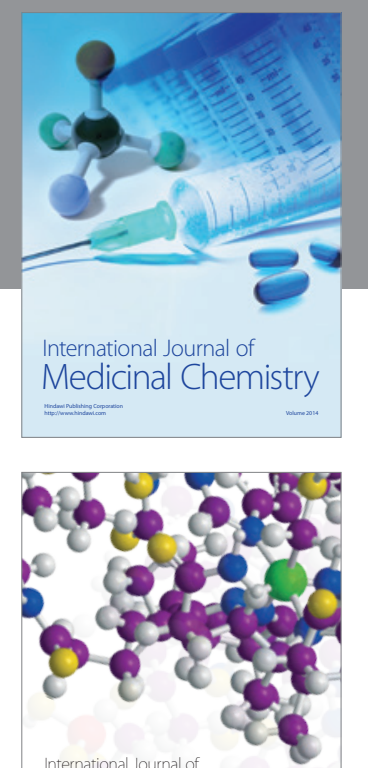

\section{Carbohydrate} Chemistry

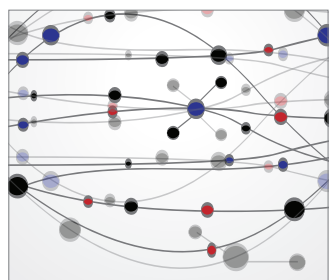

The Scientific World Journal
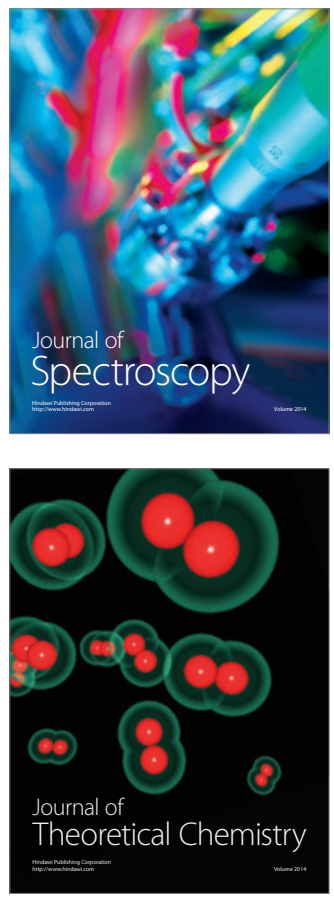
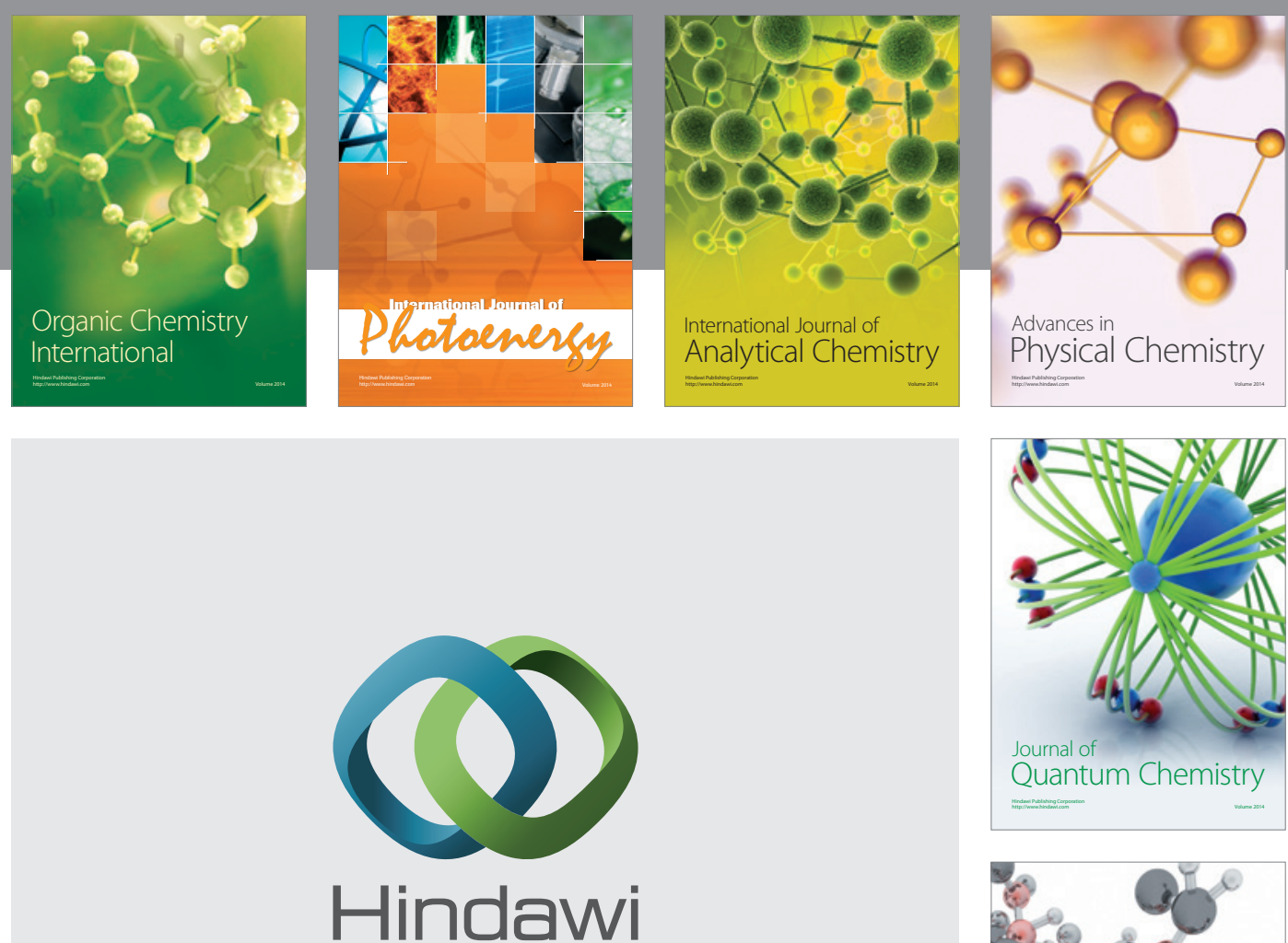

Submit your manuscripts at

http://www.hindawi.com

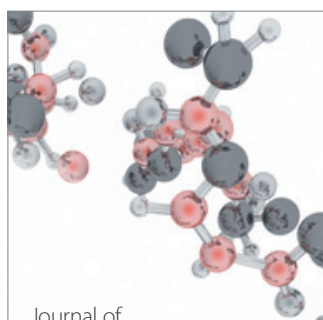

Analytical Methods

in Chemistry

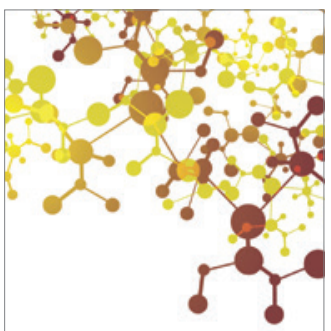

Journal of

Applied Chemistry

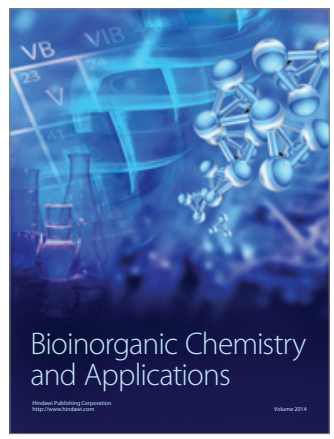

Inorganic Chemistry
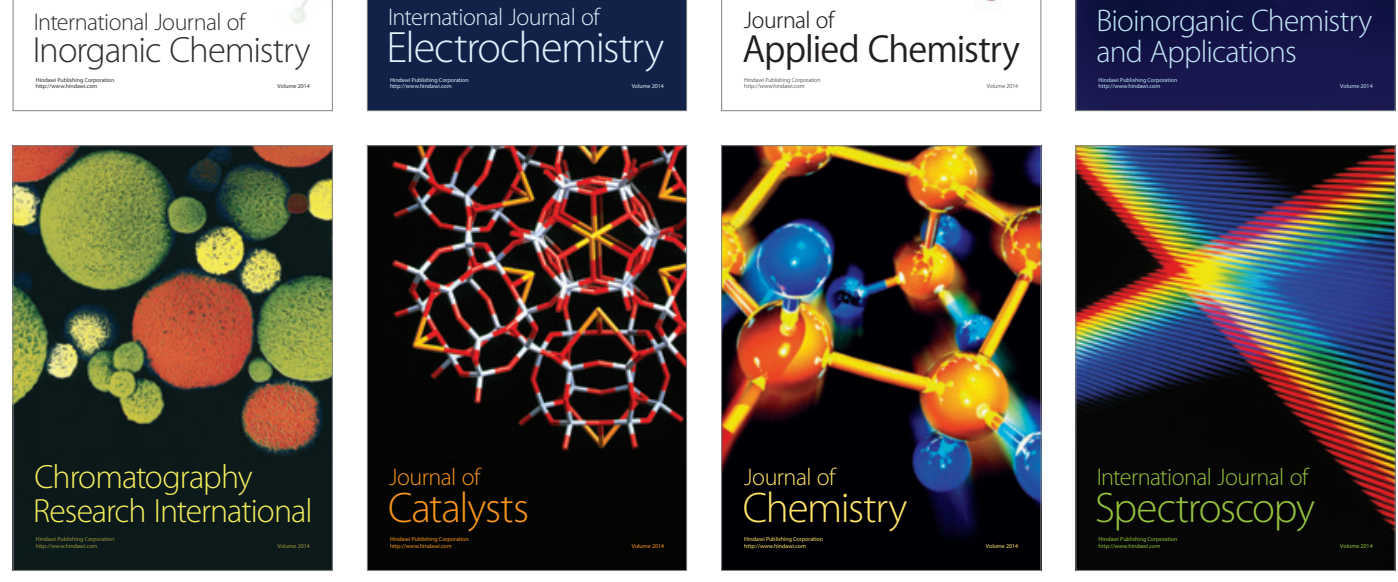